Research Article

\title{
Thermogravimetric Analysis and Kinetics of Mixed Combustion of Waste Plastics and Semicoke
}

\author{
Xiangdong Xing, ${ }^{1,2}$ Sha Wang $\mathbb{D}^{1,2}$ and Qiuli Zhang $\mathbb{D}^{1,2}$ \\ ${ }^{1}$ School of Metallurgical Engineering, Xi'an University of Architecture and Technology, Xi'an 710055, China \\ ${ }^{2}$ Research Center of Metallurgical Engineering \& Technology of Shaanxi Province, Xi'an 710055, China
}

Correspondence should be addressed to Qiuli Zhang; 19778401@qq.com

Received 8 October 2018; Revised 4 April 2019; Accepted 15 April 2019; Published 12 June 2019

Academic Editor: Fateme Razeai

Copyright (C) 2019 Xiangdong Xing et al. This is an open access article distributed under the Creative Commons Attribution License, which permits unrestricted use, distribution, and reproduction in any medium, provided the original work is properly cited.

\begin{abstract}
The thermogravimetric method was applied to study the combustion characteristics of waste plastics and semicoke mixture at different heating rates with temperature ranging from room temperature to $1173 \mathrm{~K}$. Also, the kinetic parameters of combustion process were also estimated by fitting the experimental data to the calculated data. The results showed that the mixed combustion process of waste plastics and semicoke could be divided into volatile combustion stage and fixed carbon combustion stage. The addition of waste plastics could increase the comprehensive combustion characteristic index $(S)$ and flammability index $(C)$. It showed synergistic effect in the mixed combustion process. When the additive amount of waste plastics was $60 \%$, the $S$ value and $C$ value reached peak point at the heating rate of $20 \mathrm{~K} / \mathrm{min}$. The heating rate had a promotion effect on combustion rate. The mixed combustion process of waste plastics and semicoke could be well simulated by the n-order rate model of double parallel reactions. The activation energies $E$ in the first stage of combustion of the mixture were higher than that in the second stage, and the preexponential factor $k$ was opposite. Meanwhile, a marked kinetic compensation effect was presented between the activation energy and the preexponential factor.
\end{abstract}

\section{Introduction}

The enormous use of plastic products in daily life has caused more and more serious "white pollution" problems, environmental pollution, and ecological damage. It has practical significance to recycle waste plastics to solve environmental problems and ease energy supply [1]. Common waste plastics treatment ways include incineration and landfill. However, both of the methods can produce secondary pollution. So, it is urgent to develop the new practicable and sustainable treatment technologies. Semicoke is a kind of coal conversion product with low fixed carbon content and sulfur content. Because of the good combustion performance, some iron and steel enterprises have replaced pulverized coal for blast furnace injection $[2,3]$. Waste plastics are mainly composed of carbon and hydrogen elements, which can also be used as heating agent and reducing agent for blast furnace ironmaking to make full use of its thermal energy and chemical energy. Waste plastics injected to blast furnace with semicoke is a new method for reusing waste plastic [4].

In general, the research on combustion of combustible materials mainly focused on the combustion characteristics of waste plastics, biomass, pulverized coal, and so on. Yi et al. [5] studied the cocombustion of biomass and biochar; it was cleared that the addition of biomass could promote the combustion of biochar. When the mass fraction of mixed biomass was $10 \%-30 \%$, the combustion characteristic was the optimal. Zhang et al. [6], based on thermogravimetric analysis and mass spectrometry analysis, analyzed the cocombustion characteristics and mixing optimization of tobacco stems and high-sulfur bituminous coal. It proved that the combustion of tobacco stems was more complicated than that of high-sulfur bituminous coal, and when the mixing ratio of tobacco stems was $0 \%-20 \%$, the cocombustion characteristics was best. Fei et al. [7] studied the kinetics of cocombustion of biomass and plastic under the condition of total oxygen by thermogravimetric analysis and 
found that plastic could reduce the combustion temperature of wood chips. Fan-Fei et al. [8] analyzed the mixed combustion characteristics of biomass and coal with different degrees of deterioration. It concluded that biomass had lower combustion characteristic temperatures and better combustion characteristics than coal. However, there are few reports on the mixed combustion of waste plastics and semicoke. The influence of waste plastics on the combustion of semicoke is not yet clear. It is of great significance to study the combustion characteristics of waste plastics and semicoke mixture.

Thermogravimetric analysis technology is widely used because of its simple operation process and large amount of data [9-13]. Some combustion characteristic values such as ignition temperature, burnout temperature, peak reaction temperature, maximum combustion rate, average combustion rate, and combustion time can be obtained through thermogravimetric analysis. In addition, according to the weight loss curves at different temperatures, activation energy, preexponential factor, and other combustion kinetic parameters can be determined. Kinetic analysis can deeply study the combustion mechanism of substances and predict the combustion rate and reaction process. Therefore, it is promising to study the combustion of the mixture through kinetic analysis.

In the present study, the similarities and differences of waste plastics and semicoke were analyzed by proximate analysis and ultimate analysis. At the same time, the combustion characteristics of the mixture of waste plastics and semicoke were discussed by thermogravimetric analysis at different heating rates. In order to further investigate the combustion mechanism, the ignition temperature, burnout temperature, peak reaction temperature, ignition index, and comprehensive combustion index of the mixture were obtained by TG and DTG curves. The synergistic effect between the combustion of the mixture was also researched. Moreover, the kinetic parameters during the combustion process were calculated by the n-order rate model of double parallel reactions. The studies provided theoretical basis for the application of waste plastics with semicoke injected into blast furnace and had a good benefit to relieve the pressure of environmental protection caused by waste plastics at the same time.

\section{Materials and Methods}

2.1. Raw Materials. Semicoke and waste plastic were used as raw materials in the experiment. The proximate analysis and ultimate analysis according to Perkin Elmer EA-2400 elemental analyzer and 5E-MAC III infrared rapid coal quality analyzer are shown in Table 1 . It can be seen from Table 1 that the volatile content of waste plastics is far greater than that of semicoke, and the ash content is opposite. The sulfur content is 0 , which means its pollution is small, and has good advantages for blast furnace injection.

2.2. Thermogravimetric Analysis. The tests were carried on TGA209F3 thermogravimetric analyzer produced by
TABle 1: Proximate analysis and ultimate analysis of waste plastic and semicoke.

\begin{tabular}{lcccccccc}
\hline \multirow{3}{*}{ Samples } & \multicolumn{3}{c}{$\begin{array}{c}\text { Proximate analysis } \\
\text { (wt.\%) }\end{array}$} & \multicolumn{4}{c}{$\begin{array}{c}\text { Ultimate analysis } \\
\text { (wt.\%) }\end{array}$} \\
& $\mathrm{V}_{\mathrm{ad}}$ & $\mathrm{A}_{\mathrm{ad}}$ & $\mathrm{FC}_{\mathrm{ad}}$ & $\mathrm{C}$ & $\mathrm{H}$ & $\mathrm{O}$ & $\mathrm{N}$ & $\mathrm{S}$ \\
\hline WP & 98.81 & 0.91 & 0.28 & 80.70 & 13.74 & 2.18 & 0.81 & 0 \\
NKC & 7.48 & 16.87 & 75.65 & 77.66 & 1.20 & 0.79 & 4.75 & 0.24 \\
\hline
\end{tabular}

Note. WP is waste plastic, NKC is semicoke.

German NETZSCH company under a flowing air atmosphere. The temperature changed from the ambient temperature to $1173 \mathrm{~K}$ with the heating rates of $2.5 \mathrm{~K} / \mathrm{min}, 5 \mathrm{~K} /$ $\mathrm{min}, 10 \mathrm{~K} / \mathrm{min}$, and $20 \mathrm{~K} / \mathrm{min}$, respectively. The sample weight was approximately $10 \mathrm{mg}$ and was placed in an $\mathrm{Al}_{2} \mathrm{O}_{3}$ crucible. Then, the $\mathrm{Al}_{2} \mathrm{O}_{3}$ crucible was placed in a TG bracket.

The samples used in the study were dried under the sun for 7 days to separate out water. The semicoke was shredded into particles in sizes of about $5 \mathrm{~mm}$ and subsequently crushed to $-0.200 \mathrm{~mm}$ in a self-designed crushing system. Afterward, the particle sizes of samples were selected to that lower than $0.074 \mathrm{~mm}$ by using standard test sieve. Waste plastics were made of mineral water bottles commonly used in life, after washing, drying, low-temperature soft melting, and cooling treatment, the -200 mesh waste plastics powder was obtained. The particle shape and surface structure of semicoke and waste plastics samples obtained with SEM are shown in Figure 1. The mixtures were prepared according to the proportion of $100 \%, 80 \%, 60 \%, 40 \%, 20 \%$ and $0 \%$ of waste plastic powder. Then they were ground for 20 minutes to mix evenly.

From Figure 1, significant differences among two samples can be seen. The semicoke sample exists in particle form with nonuniform surface, some of them with the smooth surface and sharp edges and another in shape with smaller randomly oriented pores. The waste plastic sample is mainly composed of irregular round particles with a smooth surface. Small round particles gathered around large particles.

The combustion rate of the mixture was calculated by

$$
x=\frac{\left(m_{0}-m_{t}\right)}{\left(m_{0}-m_{\infty}\right)}
$$

where $m_{0}$ represents the initial mass of the sample, $m_{t}$ represents the mass of the sample at time $t$ during combustion, and $m_{\infty}$ represents the final mass of sample combustion.

2.3. Kinetic Model. The kinetic model of the mixed combustion in this paper is based on two important assumptions [14]. First, the sample consists of different components, and the property of every component is also different. The reactivity of the unit surface varies with the sample burning out. Assuming that the mixture of waste plastics and semicoke has different reaction properties, the mass of the mixture during combustion can be described as follows: 

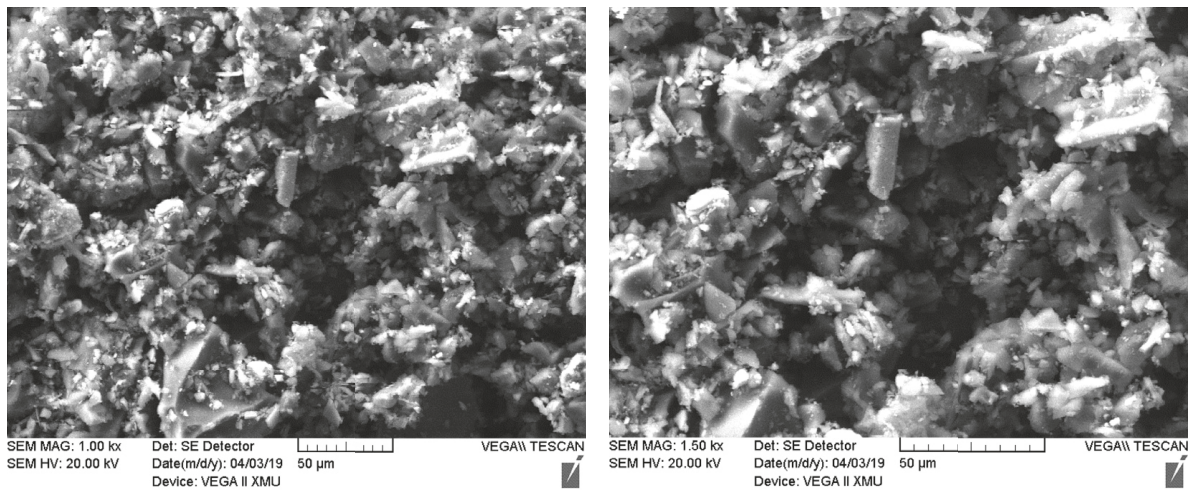

(a)
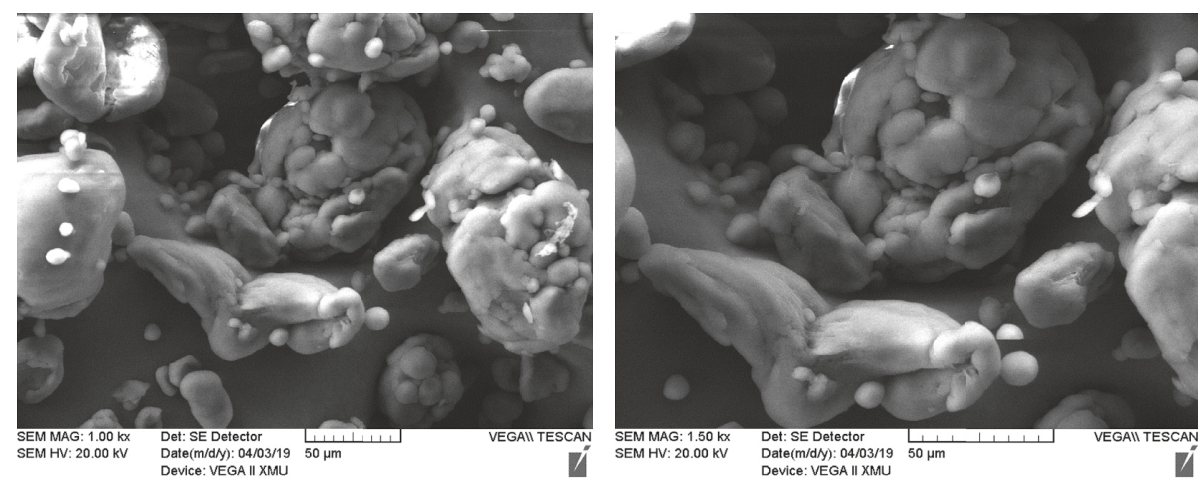

(b)

Figure 1: SEM of the samples (a) semicoke (b) waste plastic.

$$
m_{t}=\sum_{i=1}^{n} c_{i} \times x_{i}+m_{\infty}
$$

where $c_{i}$ is the fraction of combustible material in component $i, x_{i}$ is the reaction fraction of component $i$ at time $t$, and $n$ is the number of components.

Secondly, it is assumed that the mixed combustion process of waste plastics and semicoke is a gas-solid noncatalytic heterogeneous reaction, and the reaction rate of the sample can be expressed as follows:

$$
\frac{d x}{d t}=k\left(p_{\mathrm{g}}, T\right) f(x)
$$

where $k$ represents the apparent reaction rate constant and is related to the reaction temperature $T$ and the gas phase partial pressure $P_{\mathrm{g}}$.

In this experiment, $f(x)$ is assumed to be the $n$-th order reaction rate model, which can be described by

$$
f(x)=(1-x)^{n} .
$$

During this process, if the gas phase partial pressure $P_{\mathrm{g}}$ remains invariant, the apparent reaction rate constant depends on the reaction temperature $T$ and can be expressed by the Arrhenius equation, which can be described by

$$
k=k_{0} e^{-E / R T},
$$

where $k_{0}$ refers to the preexponential factor, $E$ is activation energy, and $R$ is the gas constant. In the case of a single independent parallel reaction, the total reaction rate is calculated as follows:

$$
\frac{d x}{d t}=\sum_{1}^{i} c_{i}\left(\frac{d x_{i}}{d_{t}}\right), \quad i=1,2,3, \ldots
$$

Substitute formulas (3)-(5) in (6) to obtain

$$
\frac{d x}{d t}=\sum_{1}^{i} c_{i} \cdot k_{i} e^{-E_{i} / R T} \cdot\left(1-x_{i}\right)^{n_{i}}, \quad i=1,2,3, \ldots
$$

The combustion rate of the mixture can be obtained from the average combustion rate values of the various components according to formula (7). The more the number of combustion components, the higher the accuracy of the model. However, $c_{i}, k_{i}, E_{i}$, and $n_{i}$ are all required to calculate for every component, which requires a lot of calculation work. Due to the lack of experimental data and convergence conditions, different results may be obtained, such as premature convergence, slow convergence, or nonconvergence.

By analyzing the combustion characteristic curves of the mixture, the combustion process of waste plastics and semicoke mixture can be divided into volatile combustion stage and fixed carbon combustion stage. Therefore, in order to reduce the amount of calculation and maintain the accuracy of the model in combination with the conclusions of Biney et al. [15], this paper uses the n-order rate model of double parallel reactions to study the kinetics of the combustion process. So equation (7) can be converted into 
equation (8) to simulate the two stages of the combustion process:

$$
\begin{aligned}
\frac{d_{x}}{d_{t}}= & \sum_{1}^{i} c_{1} \cdot k_{1} \cdot e^{-E_{1} / R T} \cdot\left(1-x_{1}\right)^{n_{1}} \\
& +\sum_{1}^{i} c_{2} \cdot k_{2} e^{-E_{2} / R T} \cdot\left(1-x_{2}\right)^{n_{2}}, \quad i=1,2,3, \ldots,
\end{aligned}
$$

where $c_{1}$ and $c_{2}$, respectively, represent the percentage of volatile content and fixed carbon content, and the relationship between them is shown in the following equation:

$$
c_{1}+c_{2}=1 \text {. }
$$

Under nonisothermal conditions, the relationship between sample temperature and combustion time is shown in the following equation:

$$
T=T_{0}+\beta t
$$

where $T_{0}$ is the initial temperature and $\beta$ is the heating rate, $\mathrm{K} / \mathrm{min}$.

Substituting formula (10) in formula (8) and integrating gives

$$
\int_{0}^{x} \frac{d x}{(1-x)^{n_{1}}}=\frac{c_{1} k_{1}}{\beta} \int_{T_{0}}^{T} e^{-E_{1} / R T} d T+\frac{c_{2} k_{2}}{\beta} \int_{T_{0}}^{T} e^{-E_{2} / R T} d T
$$

When $n=1$, equation (11) can be converted into:

$$
x=\sum_{i=1}^{2} c_{i} \cdot\left(1-\exp \left(\frac{k_{i}}{\beta} \exp \left(-\frac{E_{i}}{R T}\right) \cdot\left(T-T_{0}\right)\right)\right) .
$$

When $n \neq 1$, equation (11) can be converted into

$$
x=\sum_{i=1}^{2} c_{i}\left(1-\left(1-\left(1-n_{i}\right) \frac{k_{i}}{\beta} \exp \left(-\frac{E_{i}}{R T}\right) \cdot\left(T-T_{0}\right)^{1 /\left(1-n_{i}\right)}\right)\right) \text {. }
$$

Nonlinear least square fitting is performed on equations (12) and (13) to minimize the objective function of equation (14) to determine eight dynamic parameters $\left(c_{1}, c_{2}, k_{1}, k_{2}, E_{1}\right.$, $E_{2}, n_{1}$, and $n_{2}$ ). The whole calculation process is executed by a program compiled by $\mathrm{C}++$.

$$
\mathrm{OF}=\sum_{m=1}^{M}\left(\frac{x_{\exp , m}-x_{\mathrm{calc}, m}}{x_{\exp , m}}\right)^{2}
$$

where $x_{\exp , m}$ is the experimental value corresponding to the temperature $T_{m}, x_{\text {calc } m}$ is the calculated value corresponding to the temperature $T_{m}$, and $M$ is the number of data points.

The mixed combustion process of waste plastics and semicoke is very complex, and there is relative error between the calculated value and the experimental value. By comparing them, the relative error is calculated by the following equation:

$$
\operatorname{DEV}(\%)=100 \times \frac{\left(\sum_{m=1}^{M}\left(x_{\text {exp }, m}-x_{\text {calc }, m}\right)^{2} / M\right)^{1 / 2}}{\max (x)_{\exp }},
$$

where $\operatorname{DEV}(\%)$ is relative error, $x_{\exp , m}$ is experimental value, $x_{\text {calc }, m}$ is calculated value, $\max (x)_{\exp }$ is the maximum conversion rate of experiment, and $M$ is the number of data points.

\section{Results and Discussion}

3.1. Thermogravimetric Analysis of Waste Plastic and Semicoke. The TG and DTG curves of waste plastics and semicoke mixture at $10 \mathrm{~K} / \mathrm{min}$ heating rate are shown in Figures 2 and 3, respectively.

The TG curves of the mixture were between individual waste plastic and semicoke sample. With the increase of the amount of waste plastics, the TG curves of the mixture moved to the low-temperature zone and varied with the content of waste plastic. However, the trend of the TG curves of the mixture took into account the characteristics of the individual sample. The combustion weightlessness process of waste plastics and semicoke mixture could be divided into volatile combustion stage and fixed carbon combustion stage. Because the semicoke was fully dried, the water content of waste plastics was negligible which meant there was no dehydration process. An initial stage of combustion existed between ambient temperature and $654.86-678.26 \mathrm{~K}$ due to the softening of waste plastics and semicoke as well as the precipitation of volatile matter. Then the largest peak was observed at 743.27-752.35 K. In this stage, the mixture of waste plastic and semicoke thermally decomposed a large amount of volatile matter and burned rapidly. Finally, the temperature rose to 910.24-918.27 K. The loss of weight mainly was due to the combustion of fixed carbon in the mixture, which was called the second stage.

It was very complicated to analyze the mixed combustion process of waste plastics and semicoke. In order to determine whether there was synergistic effect in the mixed combustion process, the average conversion value of waste plastics conversion and semicoke conversion in the single combustion process was compared with the experimental value. The synergistic effect is positive when the experimental value is higher than the calculated value. When the experimental value is lower than the calculated value, the synergistic effect is negative [16]. When the experimental value is the same as the calculated value, it means that there is no synergistic effect. The existence of synergistic effect is related to the difference between the calculated value and the experimental value.

Assuming that there was no interaction between the mixture, the overall mass loss of the mixture was the average mass loss of the individual (calculated by formula (16)):

$$
X_{\text {caculated }}=\alpha x_{\mathrm{wp}}+\beta y_{\mathrm{nkc}} \text {. }
$$

In formula (16), $a$ and $\beta$ were the mass percentage of waste plastic and semicoke in the mixture, respectively.

The comparison between the calculated data and the experimental data is shown in Figure 3.

It could be found from Figure 4 that the calculated data and the experimental data had good similarity, but 


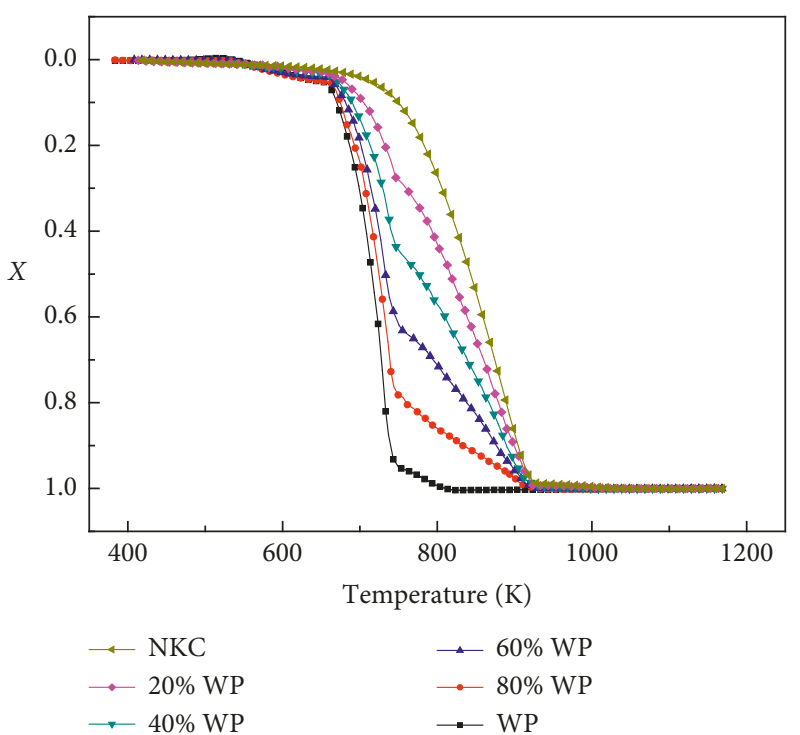

Figure 2: TG curves at $10 \mathrm{~K} / \mathrm{min}$ heating rate.

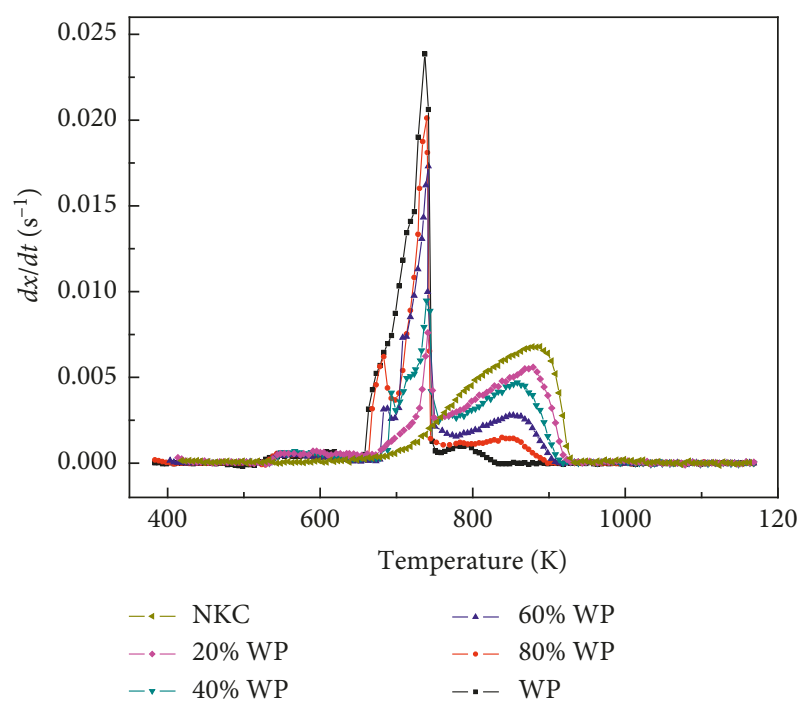

Figure 3: DTG curves at $10 \mathrm{~K} / \mathrm{min}$ heating rate.

deviation between the calculated data and experimental data demonstrates that waste plastics interacted with semicoke. There was synergistic effect in the combustion process of waste plastics and semicoke mixture. The experimental value in the first stage was lower than the calculated value, and the effect was negative. The experimental value in the second stage was higher than the calculated value, and the effect was positive.

In order to further investigate the effect of waste plastics addition on the combustion process of semicoke, the combustion characteristic value was ascertained by TG and DTG curves. The comprehensive combustion characteristic index $(S)$ covers some main characteristic index during combustion and comprehensively reflects the combustion characteristics of pulverized coal. The higher the value of $S$, the better the combustion characteristics, as defined in the following equation:

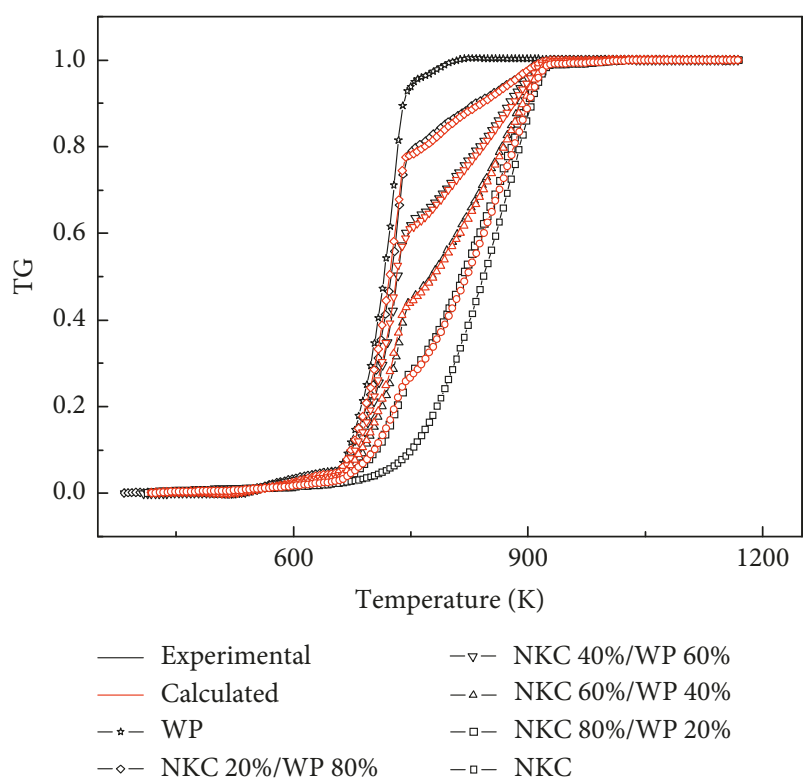

FIgURE 4: Comparison between experimental data and calculated values $(10 \mathrm{~K} / \mathrm{min})$.

$$
S=\frac{R_{\max } \times R_{\text {mean }}}{T_{i}^{2} \times T_{\mathrm{h}}},
$$

where $R_{\max }$ is the maximum combustion rate, $\mathrm{s}^{-1}, R_{\text {mean }}$ is the average combustion rate, $\mathrm{s}^{-1}, T_{i}$ is the ignition temperature, $\mathrm{K}$, and $T_{\mathrm{h}}$ is the burnout temperature, $\mathrm{K}$.

$\mathrm{C}$ indicates the difficulty of igniting the combustibles, and the larger the value, the better the flammability of the coal. Flammability index $\mathrm{C}$ is mainly related to $R_{\max }$ and $T_{i}$. It is defined as

$$
C=\frac{R_{\max }}{T_{i}^{2}}
$$

The combustion characteristic values of the mixture at a heating rate of $10 \mathrm{~K} / \mathrm{min}$ are shown in Table 2 .

It could be seen from Table 2 that the ignition temperature $\left(T_{i}\right)$ and burnout temperature $\left(T_{\mathrm{f}}\right)$ of waste plastics were lower than those of semicoke. As waste plastics fraction was increased from 0 to $100 \%, T_{i}$ and $T_{\mathrm{f}}$ slightly decreased from $568.25 \mathrm{~K}$ to $563.554 \mathrm{~K}$ and $978.257 \mathrm{~K}$ to $798.554 \mathrm{~K}$. The lower the initial temperature, the more flammable of the combustible materials, which indicated that the addition of waste plastics could facilitate the combustion of semicoke. Meanwhile, $R_{\max -1}$ and $R_{\max -3}$ decreased, but $R_{\max -2}$ increased, while the maximum burning rate $\left(R_{\max }\right)$ decreased. When $0 \%$ of waste plastic content is added, the maximum burning rate $\left(R_{\max }\right)$ is $0.0068 \mathrm{~s}^{-1}$, which is the lowest. With increase of waste plastic content, flammability index $C$ of the mixture increased, while it showed the same change law of comprehensive combustion characteristic index S. From these results, it could be concluded that comprehensive combustion characteristics of semicoke could be improved by addition of waste plastics, while it was the same as ignition property, which provided a theoretical basis for blast furnace injection of waste plastics and semicoke. 
TABLE 2: Combustion characteristic values of mixtures at a heating rate of $10 \mathrm{~K} / \mathrm{min}$.

\begin{tabular}{|c|c|c|c|c|c|c|}
\hline Samples & WP & WP $80 \%$ & WP $60 \%$ & WP $40 \%$ & WP $20 \%$ & NKC \\
\hline$T_{i}(\mathrm{~K})$ & 563.554 & 553.319 & 558.228 & 557.96474 & 563.79207 & 568.257 \\
\hline$T_{1}(\mathrm{~K})$ & 663.55 & 668.319 & 683.228 & 693.10 & - & - \\
\hline$R_{\max -1}\left(\mathrm{~s}^{-1}\right)$ & 0.00315 & 0.00316 & 0.00313 & 0.0041 & - & - \\
\hline$T_{2}(\mathrm{~K})$ & 741.97 & 740.56 & 740.95 & 744.07 & 747.24 & - \\
\hline$R_{\max -2}\left(\mathrm{~s}^{-1}\right)$ & 0.02062 & 0.0181 & 0.00998 & 0.00888 & 0.0077 & - \\
\hline$T_{3}(\mathrm{~K})$ & 793.55 & 838.32 & 853.23 & 858.46 & 863.49 & 885.17 \\
\hline$R_{\max -3}\left(\mathrm{~s}^{-1}\right)$ & 0.00105 & 0.00149 & 0.00279 & 0.0047 & 0.00565 & 0.0068 \\
\hline$T_{m}(\mathrm{~K})$ & 741.97 & 740.56 & 740.95 & 744.07 & 747.24 & 885.17 \\
\hline$T_{\mathrm{h}}(\mathrm{K})$ & 798.554 & 910.81731 & 918.10897 & 930.69712 & 933.492 & 978.257 \\
\hline$R_{\max }\left(\mathrm{s}^{-1}\right)$ & 0.02062 & 0.0181 & 0.00998 & 0.00888 & 0.0077 & 0.0068 \\
\hline$R_{\text {mean }}\left(\mathrm{s}^{-1}\right)$ & 0.00827 & 0.007583 & 0.0053 & 0.00589 & 0.005845 & 0.0068 \\
\hline$C \times 10^{-8}$ & 6.49258 & 5.9119 & 3.20263 & 2.85233 & 2.42246 & 2.10581 \\
\hline$S \times 10^{-13}$ & 6.72386 & 4.92195 & 1.8488 & 1.80512 & 1.73219 & 1.46378 \\
\hline
\end{tabular}

Note. $T_{i}$ is the ignition temperature; $T_{1}, T_{2}$, and $T_{3}$ are the reaction peak temperatures of the first, second, and third peaks; $T_{\mathrm{h}}$ is the burnout temperature; $R_{\max -1}, R_{\max -2}$, and $R_{\max -3}$ are reaction rates corresponding to $T_{1}, T_{2}$, and $T_{3} ; R_{\max }$ is the maximum reaction rate; $R_{\operatorname{mean}}$ is the average combustion rate; $C$ is flammability index; and $S$ is the comprehensive combustion characteristic index.

\subsection{Effect of Heating Rate on Combustion Process of Mixture.} The TG and DTG curves of the mixture adding $60 \%$ waste plastics content at different heating rates are shown in Figures 5 and 6 , respectively.

As the heating rate increased from 2.5 to $20 \mathrm{~K} / \mathrm{min}$, it was found that TG and DTG curves both moved to the hightemperature zone, resulting in thermal hysteresis phenomenon [17]. There were two main reasons for this phenomenon. On the one hand, with the increase of heating rate, the temperature raised faster, and the single reaction did not have enough time to react and overlap with the adjacent high temperature reaction. On the other hand, the overall temperature gradient of the sample cross section increased at a higher heating rate, which resulted in a large temperature difference between the inside and outside of the sample, and the surface combustion products were too late to diffuse, which hindered the combustion of internal combustibles to affect the heat transfer between the thermogravimetric instrument and the sample.

The combustion characteristics parameters of the mixture adding $60 \%$ waste plastics content at different heating rates are shown in Table 3.

When heating rate increased from $2.5 \mathrm{~K} / \mathrm{min}$ to $20 \mathrm{~K} /$ $\min , T_{i}$ and $T_{\mathrm{f}}$, respectively, increased from $527.982 \mathrm{~K}$ to $568.496 \mathrm{~K}$ and from $832.982 \mathrm{~K}$ to $933.496 \mathrm{~K}$. But the rise of both $T_{i}$ and $T_{\mathrm{f}}$ often means deterioration of combustion property. Therefore, the effect of the heating rate on the combustion process could not be judged only by the law of $T_{i}$ and $T_{\mathrm{f}}$. This paper also analyzed the influence of heating rate on the combustion performance of the mixture by flammability index $C$ and comprehensive combustion characteristic index $S$. Meantime, it could be concluded from Table 3 that $C$ value and $S$ value both increased with increasing heating rate. When heating rate increased from $2.5 \mathrm{~K} / \mathrm{min}$ to $20 \mathrm{~K} / \mathrm{min}$, $C$ increased from $4.61 \times 10^{-8}$ to $5.28 \times 10^{-8}$ and $S$ increased from $3.72 \times 10^{-13}$ to $5.09 \times 10^{-13}$. In a word, it could be confirmed that with increasing heating rate, $T_{i}, T_{\mathrm{f}}, C$, and $S$ increased. Although the $T_{i}$ and $T_{\mathrm{f}}$ increased which deteriorated the combustion property of the mixture, the obvious promotion effect on

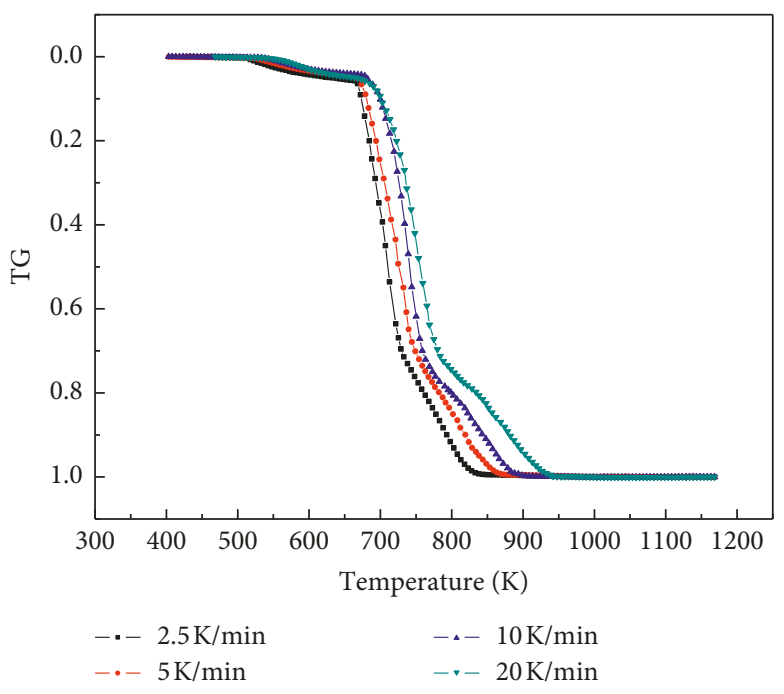

FIGURE 5: TG curves of adding 60\% waste plastics content.

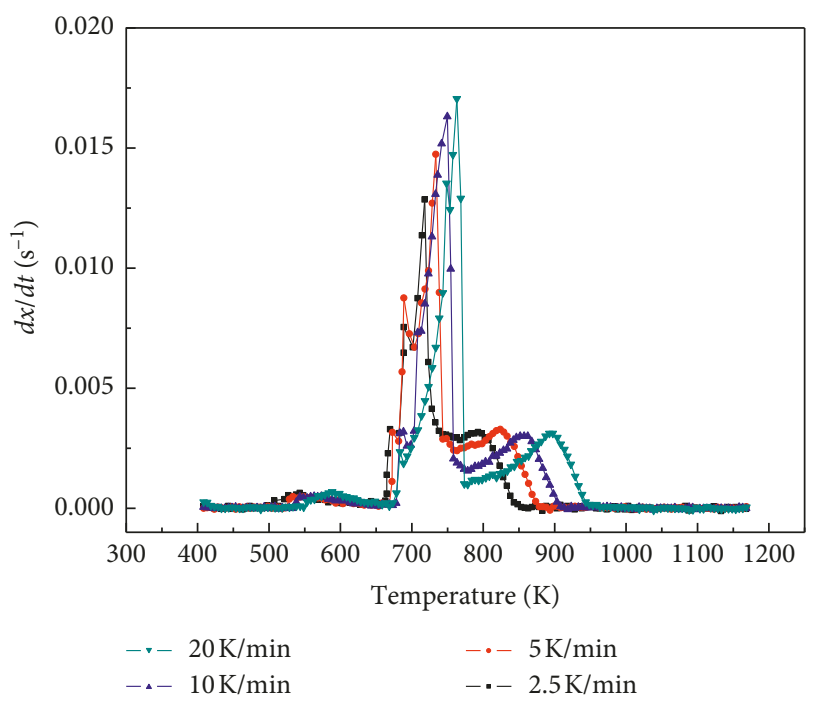

Figure 6: DTG curves of adding 60\% waste plastics content. 
TABLE 3: Combustion characteristics parameters of mixture adding $60 \%$ waste plastic content.

\begin{tabular}{|c|c|c|c|c|}
\hline $\begin{array}{l}\text { Heating rates } \\
(\mathrm{K} / \mathrm{min})\end{array}$ & 2.5 & 5 & 10 & 20 \\
\hline$T_{i}(\mathrm{~K})$ & 527.982 & 543.473 & 558.228 & 568.496 \\
\hline$T_{1}(\mathrm{~K})$ & 669.55128 & 672.86859 & 688.228 & 683.496 \\
\hline$R_{\max -1}\left(\mathrm{~s}^{-1}\right)$ & 0.00329 & 0.00316 & 0.00318 & 0.00235 \\
\hline$T_{2}(\mathrm{~K})$ & 688.62179 & 688.73397 & - & 748.496 \\
\hline$R_{\max -2}\left(\mathrm{~s}^{-1}\right)$ & 0.00754 & 0.00876 & - & 0.01353 \\
\hline$T_{3}(\mathrm{~K})$ & 717.98077 & 733.473 & 749.63141 & 763.01282 \\
\hline$R_{\max -3}\left(\mathrm{~s}^{-1}\right)$ & 0.01286 & 0.01474 & 0.01631 & 0.01705 \\
\hline$T_{4}(\mathrm{~K})$ & 792.70833 & 823.91827 & 857.13141 & 897.4359 \\
\hline$R_{\max -4}\left(\mathrm{~s}^{-1}\right)$ & 0.00317 & 0.00329 & 0.003 & 0.00312 \\
\hline$T_{m}(\mathrm{~K})$ & 719.21 & 729.7485 & 764.9969 & 773.1102 \\
\hline$T_{\mathrm{f}}(\mathrm{K})$ & 832.982 & 863.473 & 893.228 & 933.496 \\
\hline$R_{\max }\left(\mathrm{s}^{-1}\right)$ & 0.01286 & 0.01474 & 0.01631 & 0.01705 \\
\hline$R_{\text {mean }}\left(\mathrm{s}^{-1}\right)$ & 0.006715 & 0.007488 & 0.007497 & 0.009013 \\
\hline$C \times 10^{-8}$ & 4.61 & 4.99 & 5.23 & 5.28 \\
\hline$S \times 10^{-13}$ & 3.72 & 4.33 & 4.39 & 5.09 \\
\hline
\end{tabular}

combustion rate was more significant. Therefore, high heating rate could improve the combustion properties of the mixture.

\section{Kinetic Parameter Analysis}

In order to evaluate the effect of waste plastics proportion on semicoke, the $n$-order rate model of double parallel reaction was used to further understand the combustion kinetics. The combustion rate $x$ data of the mixture was fitted nonlinearly according to equation (13), and the combustion rate curves of the fitted data and the experimental data were obtained; the results are shown in Figure 7.

It could be seen from Figure 7 that the calculated data of different samples were in good agreement with the experimental data, which showed that the model had good adaptability of the mixed combustion process of waste plastics and semicoke.

The kinetics parameters were calculated, and the results are shown in Table 4.

From Table 4, it could be seen that the correlation coefficient $R^{2}$ of the mixture was greater than 0.9986 , which proved that the kinetic model could better simulate the mixed combustion of waste plastics and semicoke. The activation energies of the first stage were higher than those of the second stage, which were $64.69-78.85 \mathrm{~kJ} \cdot \mathrm{mol}^{-1}$ and $36.60-48.04 \mathrm{~kJ} \cdot \mathrm{mol}^{-1}$, respectively. It proved that the pyrolysis combustion of volatile occurred at the lowtemperature zone in the first stage because the molecular motion was slower and the energy required for molecular activation was higher. While the second stage occurred in the high-temperature range, the limiting steps changed from the interface reaction control of the first stage to the diffusion control [18], and the diffusion activation energy was lower than the interface reaction activation energy. The pyrolysis and combustion process of volatile matter in the first stage produced a porous carbon structure, which provided good conditions for oxygen diffusion into the surface in the second stage. So, the activation energy in the second stage was lower. Temperature had different effects on interfacial reaction and diffusion. The fact that the activation energy in the low-temperature range is higher than that in the high-temperature range is consistent with the research results of Okasha et al. [19].

Meanwhile, as waste plastics fraction decreased from 100 to $0 \%$, the activation energy of the two stages all increased. When the waste plastics mass ratio was $100 \%$, the lowest activation energy was obtained with the number of $64.69 \mathrm{~kJ} \cdot \mathrm{mol}^{-1}$ and $36.60 \mathrm{~kJ} \cdot \mathrm{mol}^{-1}$, respectively. As the addition of waste plastics continued to increase, the magnitude of activation energy decrease was not very large. There existed a suitable addition of waste plastics in the process of promoting the burning of semicoke. And the activation energy of the first stage had similar law with the second stage. The lower the activation energy, the higher the reaction rate. However, it could conclude that the combustion rate decreased with the decrease of waste plastic content from Table 2, which was contrary to the changing trend of activation energy. Generally speaking, the reaction rate was influenced by activation energy and preexponential factor. In the same temperature range, the lower the activation energy, the more active the molecules and the higher the reaction rate. The preexponential factor indicates the number of collisions of activated molecules. The larger the preexponential factor, the higher the reaction rate is. From Table 4, it could be concluded that the preexponential factor was large corresponding to a low activation energy, which was called compensation effect in kinetic studies. Compensation effect is a common phenomenon in gasification studies of coal, biomass, and other carbonaceous materials $[20,21]$.

In order to quantify the error caused by the kinetic model, the deviations DEV was calculated between the experimental curves and the calculated curves by equation (14). The results are shown in Table 5. It could be seen that the deviations between the experimental value and the calculated value were all lower than $1.09 \%$. It once again proved that the n-order rate model of double parallel reactions had good accuracy in representing the mixed combustion process of waste plastics and semicoke. 

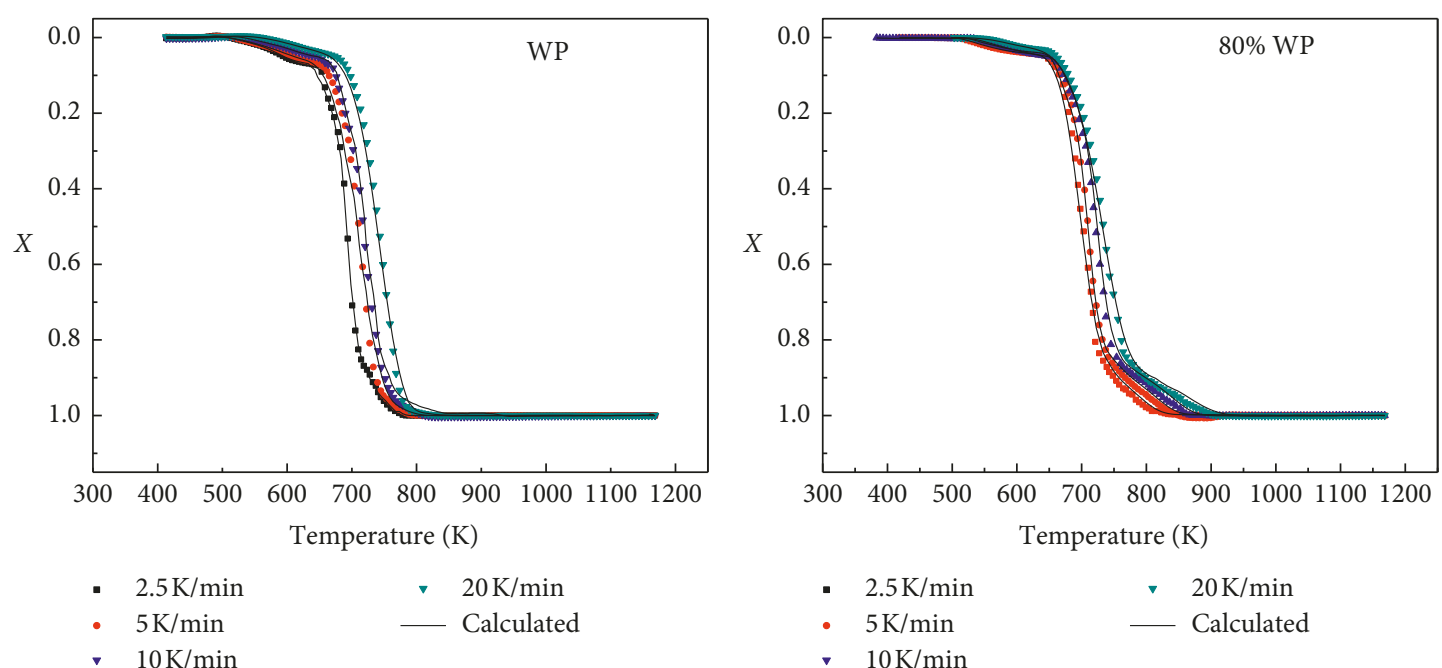

(a)

(b)
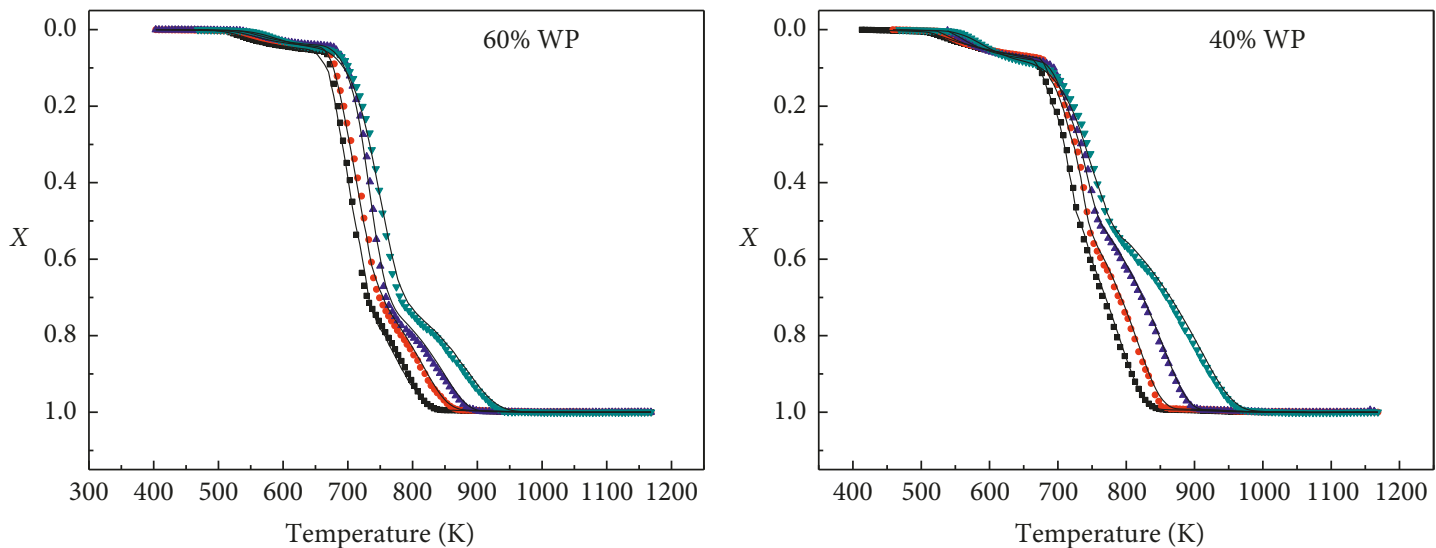

- $2.5 \mathrm{~K} / \mathrm{min}$

- $20 \mathrm{~K} / \mathrm{min}$

- $5 \mathrm{~K} / \mathrm{min}$

_ Calculated

$5 \mathrm{~K} / \mathrm{min}$

Calculated

- $10 \mathrm{~K} / \mathrm{min}$

Temperature (K)

- $5 \mathrm{~K} / \mathrm{min}$

- $20 \mathrm{~K} / \mathrm{min}$

- $10 \mathrm{~K} / \mathrm{min}$

_ Calculated

(c)

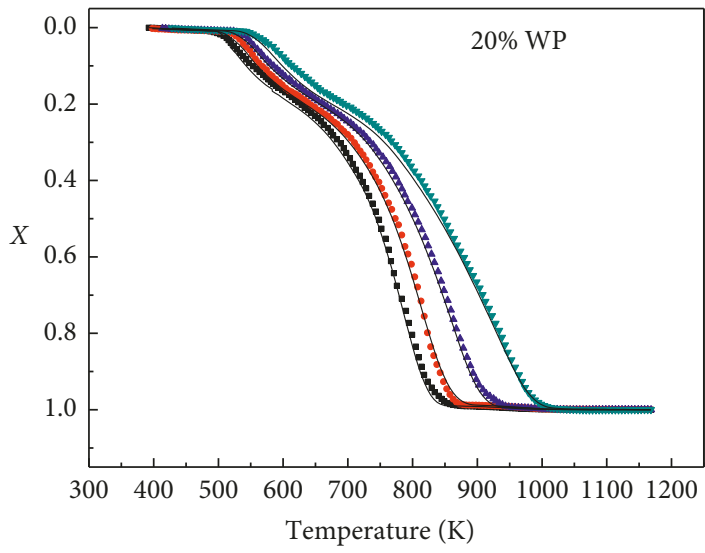

- $2.5 \mathrm{~K} / \mathrm{min}$

- $20 \mathrm{~K} / \mathrm{min}$

- $5 \mathrm{~K} / \mathrm{min}$

— Calculated

- $10 \mathrm{~K} / \mathrm{min}$

(d)
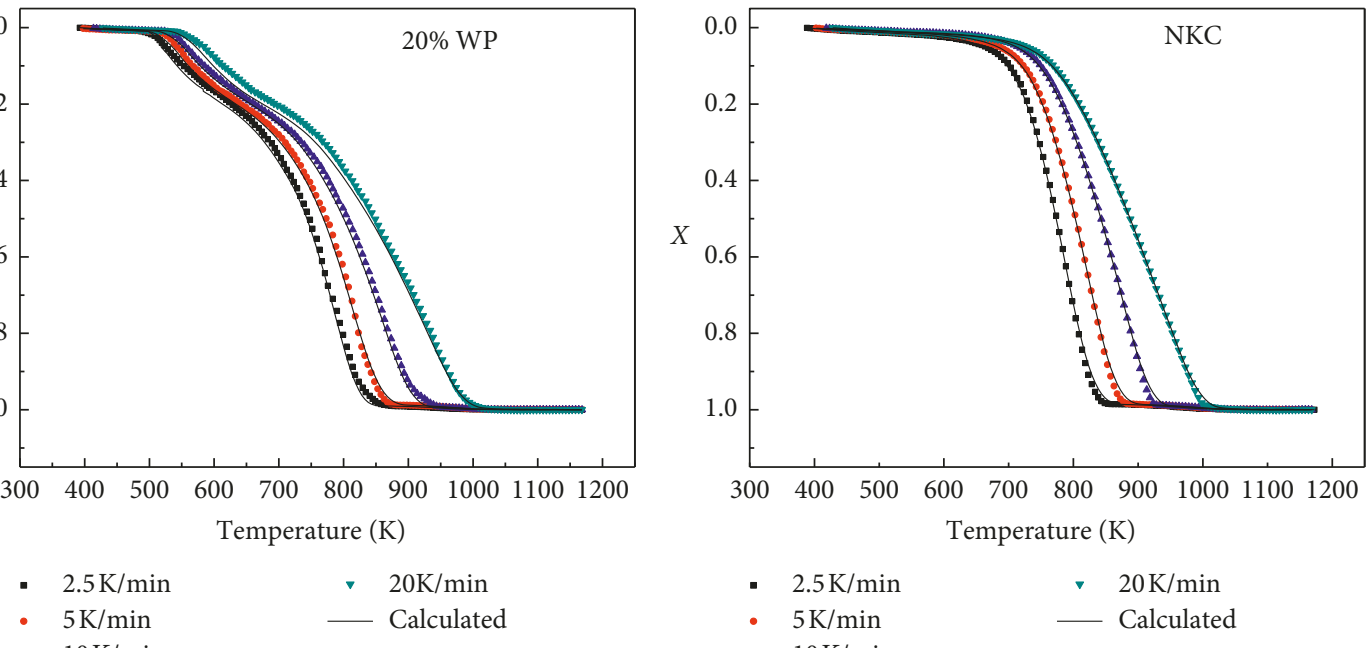

- $2.5 \mathrm{~K} / \mathrm{min}$

- $20 \mathrm{~K} / \mathrm{min}$

- $5 \mathrm{~K} / \mathrm{min}$

- Calculated

- $10 \mathrm{~K} / \mathrm{min}$

(e)

(f)

FIGURE 7: Experimental conversion curves and n-order rate calculation curves of double parallel reactions for mixture combustion at different heating rates. 
TABle 4: Combustion kinetic parameters of mixtures.

\begin{tabular}{lcccccc}
\hline Sample & $k_{1}$ & $E_{1}\left(\mathrm{~kJ} \cdot \mathrm{mol}^{-1}\right)$ & $n_{1}$ & $k_{2}$ & $E_{2}\left(\mathrm{~kJ} \cdot \mathrm{mol}^{-1}\right)$ & $n_{2}$ \\
\hline WP & 1.06 & 64.69 & 1.24 & 0.80 & 36.60 & 0.95 \\
80\% WP & 1.02 & 65.54 & 1.23 & 0.71 & 37.26 & 0.9994 \\
60\% WP & 0.92 & 66.16 & 1.30 & 0.64 & 38.86 & 0.9986 \\
40\% WP & 0.75 & 70.13 & 1.25 & 0.43 & 42.77 & 0.93 \\
20\% WP & 0.52 & 74.92 & 1.26 & 0.24 & 46.12 & 0.93 \\
NKC & 0.38 & 78.85 & 1.24 & 0.02 & 48.04 & 0.90 \\
\hline
\end{tabular}

TABLE 5: Deviation between experimented and calculated values.

\begin{tabular}{lcccccc}
\hline Sample & WP & $80 \%$ WP & $60 \%$ WP & $40 \%$ WP & $20 \%$ WP & NKC \\
\hline $\operatorname{DEV}(x) \%$ & 1.01 & 0.76 & 0.91 & 0.67 & 1.09 & 0.51 \\
\hline
\end{tabular}

\section{Conclusion}

The mixed combustion of the waste plastics and semicoke were investigated by thermogravimetric method. Results showed that mixed combustion process of waste plastics and semicoke included volatile combustion stage and fixed carbon combustion stage. With addition of waste plastics, comprehensive combustion characteristics and ignition property of semicoke could be improved. There was synergistic effect in the combustion process of waste plastics and semicoke mixture. With the increase of heating rate, the mass loss peak corresponding to the mixture combustion moved to high temperature zone, resulting in thermal hysteresis. Moreover, the largest $C$ and $S$ values of the mixture were obtained when the heating rate was $20 \mathrm{~K} /$ min, which showed that the higher the heating rate was, the better the combustion performance of the sample would be. The mixed combustion process of waste plastics and semicoke could be well simulated by the n-order rate model of double parallel reactions. The activation energy $E$ in the first stage of combustion were higher than that in the second stage, while the preexponential factor $k$ was opposite, and there was obvious kinetic compensation effect between them.

\section{Data Availability}

The data used to support the findings of this study were supplied by Xiangdong Xing under license and so cannot be made freely available. Requests for access to these data should be made to Xiangdong Xing, 610504108@qq.com.

\section{Conflicts of Interest}

The authors declare that there are no conflicts of interest regarding the publication of this paper.

\section{Acknowledgments}

The present work was financed by the National Nature Science Foundation of China (grant no. 51604209) and Scientific Research Plan Projects of Shaanxi Education Department (grant no. 16JK1442).

\section{References}

[1] J. Guo, J. Zhao, S. Qiu, X. Li, and K. Hu, "Application status and suggestion of waste plastic used in iron and steel industry," Journal of Iron and Steel Research, vol. 26, no. 6, pp. 1-4, 2014.

[2] X. Zhang, "Feasibility on semi-coke substitute for semi-coke in energy conservation and emissions reduction," Clean Coal Technology, vol. 21, no. 3, pp. 103-106, 2015.

[3] J. Yang, B. Hu, and Y. Gui, "Feasibility analysis of semi-coke as JISCO blast furnace with coal injection," Energy For Metallurgical Industry, vol. 30, no. 6, pp. 20-22, 2011.

[4] X. He, X. Zeng, D. Zhang, X. Cheng, and S. Yi, "Development of new materials for blast furnace blowing[J]," Fuel and Chemical Processes, vol. 46, no. 2, pp. 12-14, 2015.

[5] Q. Yi, F. Qi, G. Cheng et al., "Thermogravimetric analysis of co-combustion of biomass and biochar," Journal of Thermal Analysis and Calorimetry, vol. 112, no. 3, pp. 1475-1479, 2013.

[6] K. Zhang, K. Zhang, Y. Cao, and W.-P. Pan, "Co-combustion characteristics and blending optimization of tobacco stem and high-sulfur bituminous coal based on thermogravimetric and mass spectrometry analyses," Bioresource Technology, vol. 131, no. 3, pp. 325-332, 2013.

[7] B. A. Fei, J.-H. Hu, H.-L. Liu, X.-Y. Tang, and Z.-W. Liu, "Thermogravimetric analysis and kinetics of biomass and plastic co-combustion in oxygen enriched environment," Chinese Journal of Process Engineering, vol. 16, no. 6, pp. 1022-1027, 2016.

[8] M. Fan-Fei and M.-X. Zhang, "Research on combustion characteristics of biomass and coals with different ranks," Journal of China University of Mining \& Technology, vol. 34, no. 2, pp. 107-112, 2005.

[9] G.-W. Wang, J.-L. Zhang, J.-G. Shao, H. Sun, and H.-B. Zuo, "Thermogravimetric analysis of coal char combustion kinetics," Journal of Iron and Steel Research International, vol. 21, no. 10, pp. 897-904, 2014.

[10] C. Gai, Z. Liu, G. Han, N. Peng, and A. Fan, "Combustion behavior and kinetics of low-lipid microalgae via thermogravimetric analysis," Bioresource Technology, vol. 181, pp. 148-154, 2015.

[11] K. Jayaraman, M. V. Kok, and I. Gokalp, "Thermogravimetric and mass spectrometric (TG-MS) analysis and kinetics of coal-biomass blends," Renewable Energy, vol. 101, pp. 293300, 2017.

[12] X. Wang, J. Si, H. Tan, Y. Niu, C. Xu, and T. Xu, "Kinetics investigation on the combustion of waste capsicum stalks in western China using thermogravimetric analysis," Journal of 
Thermal Analysis and Calorimetry, vol. 109, no. 1, pp. 403412, 2012.

[13] J. Zhang, C. Wang, X. Jia, P. Wang, and D. Che, "Cocombustion characteristics and kinetic analysis of semicoke and bituminous coal," Journal of Chemical Industry and Engineering, vol. 5, no. 9, pp. 1-10, 2018.

[14] G. Wang, J. Zhang, J. Shao et al., "Thermal behavior and kinetic analysis of co-combustion of waste biomass/low rank coal blends," Energy Conversion and Management, vol. 124, pp. 414-426, 2016.

[15] P. O. Biney, M. Gyamerah, J. Shen, and B. Menezes, "Kinetics of the pyrolysis of arundo, sawdust, corn stover and switch grass biomass by thermogravimetric analysis using a multi-stage model," Bioresource Technology, vol. 179, pp. 113-122, 2015.

[16] N. Howaniec, A. Smoliński, K. Stańczyk, and M. Pichlak, "Steam co-gasification of coal and biomass derived chars with synergy effect as an innovative way of hydrogen-rich gas production," International Journal of Hydrogen Energy, vol. 36, no. 22, pp. 14455-14463, 2011.

[17] S. Jiang, T. Wang, H. Peng, Y. Jiang, K. Yao, and X. Wu, "Thermogravimetric and combustion dynamics of moulding fuel of woodiness and cornstalk," Journal of Central South University (Science and Technology), vol. 44, no. 10, pp. 4312-4318, 2013.

[18] H. Tian and Z. Liao, "Combustion characteristics and combustion kinetics of agriculture biomass," Transactions of the Chinese Society of Agricultural Engineering, vol. 29, no. 10, pp. 203-212, 2013.

[19] F. Okasha, G. Zaater, S. El-Emam, M. Awad, and E. Zeidan, "Co-combustion of biomass and gaseous fuel in a novel configuration of fluidized bed: combustion characteristics," Fuel, vol. 133, no. 1, pp. 143-152, 2014.

[20] G. Wang, J. Zhang, G. Zhang et al., "Experimental and kinetic studies on co-gasification of petroleum coke and biomass char blends," Energy, vol. 131, pp. 27-40, 2017.

[21] G. Wang, J. Zhang, J. Shao et al., "Experimental and modeling studies on $\mathrm{CO}_{2}$ gasification of biomass chars," Energy, vol. 114, pp. 143-154, 2016. 

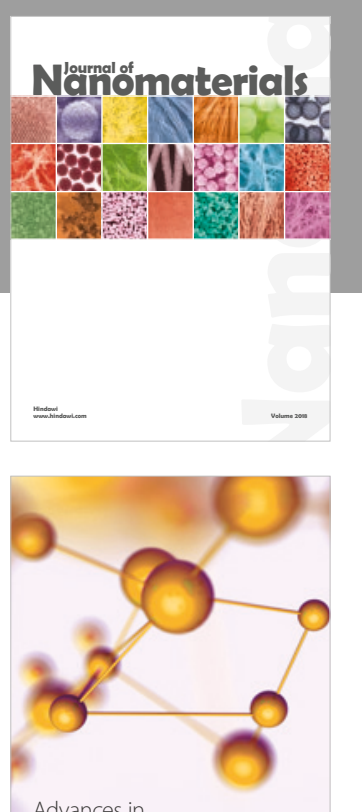

Physical Chemistry
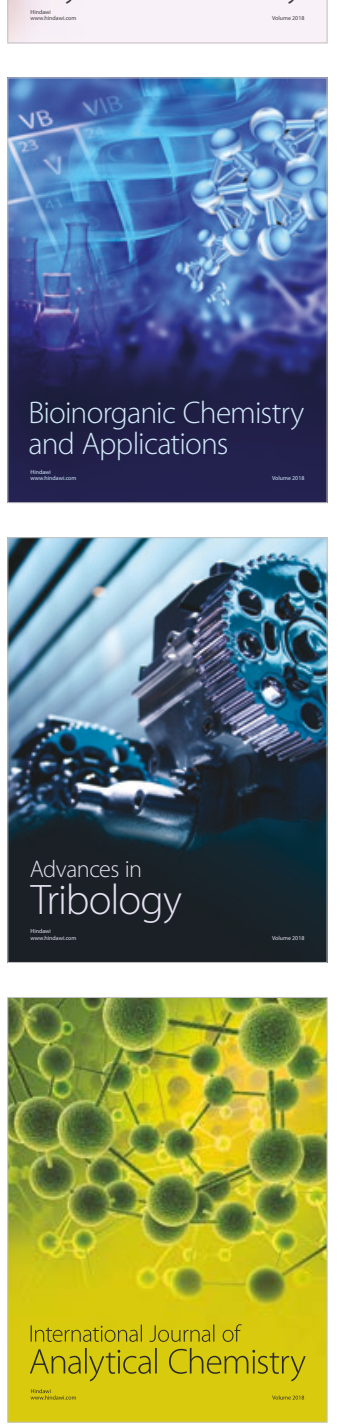

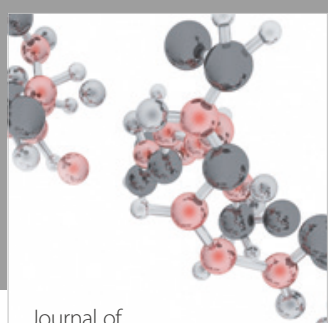

Analytical Methods

in Chemistry

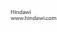

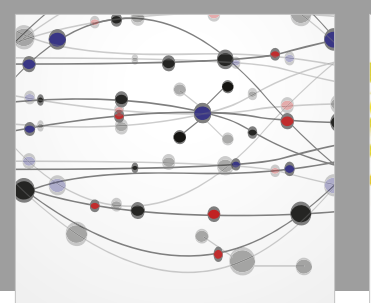

The Scientific World Journal

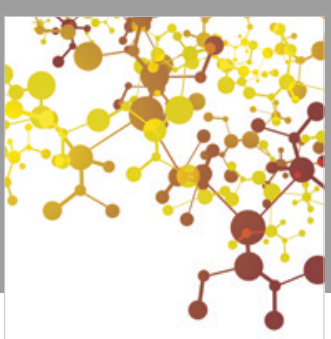

Journal of

Applied Chemistry
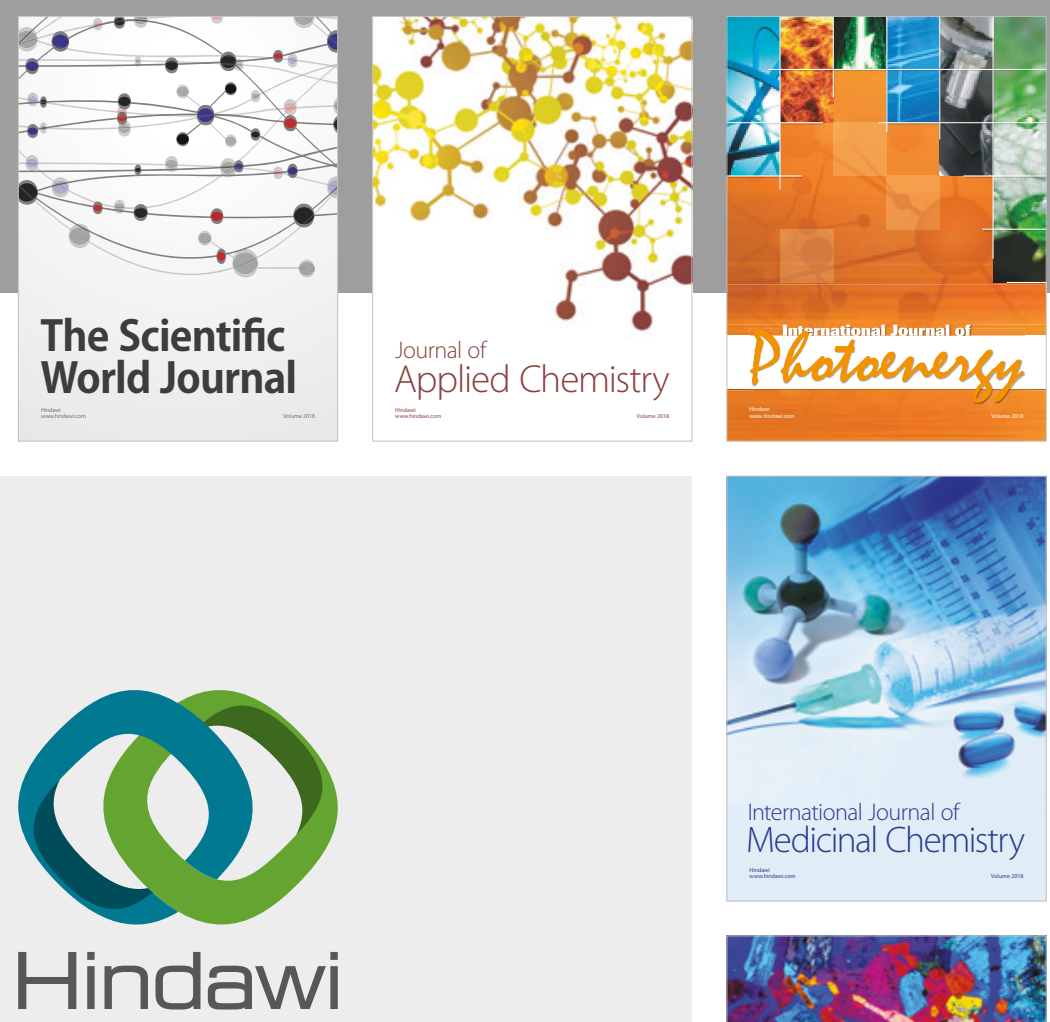

Submit your manuscripts at

www.hindawi.com
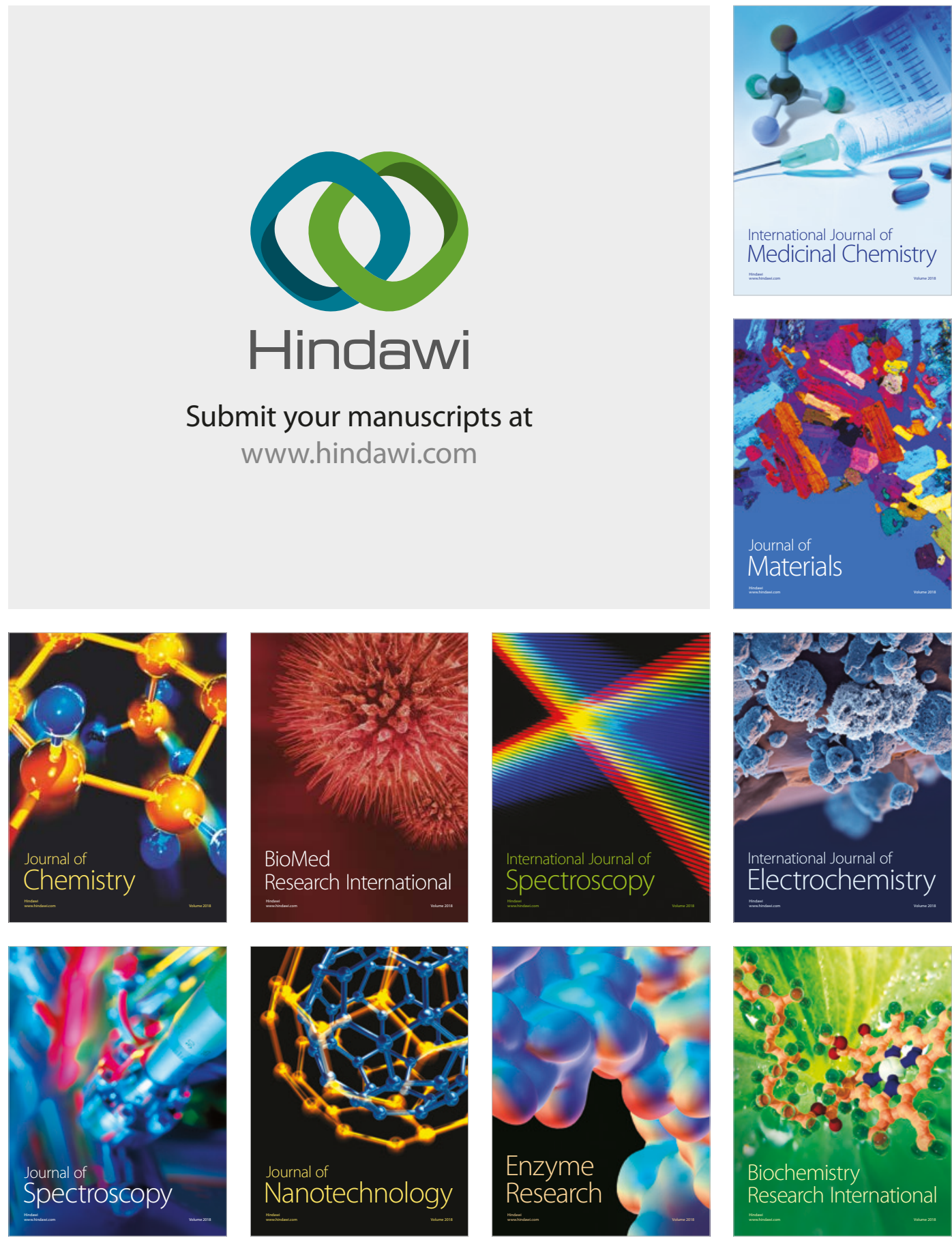
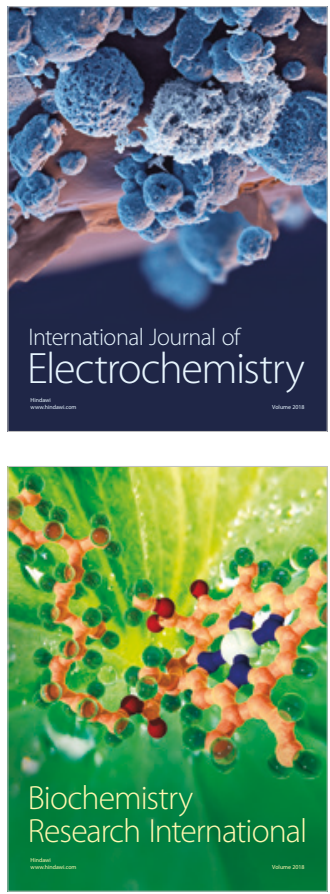